\title{
Systemic NMDA Receptor Antagonist CGP-40116 Does Not Impair Memory Acquisition but Protects against NMDA Neurotoxicity in Rhesus Monkeys
}

\author{
Sergei A. Gutnikov and David Gaffan \\ Department of Experimental Psychology, Oxford University, Oxford OX1 3UD, United Kingdom
}

A widely accepted hypothesis is that long-term potentiation (LTP) is a synaptic mechanism of memory. NMDA receptors are critically involved in induction but not maintenance of LTP; therefore, their blockade should impair memory acquisition but not retrieval. In Experiment 1, we investigated the effect of a systemic NMDA receptor antagonist, CGP-40116 [D-isomer of CGP-37849: (E)-2-amino-4-methyl-5-phosphono-3-pentenoic acid (6 mg/kg, i.m.) $60 \mathrm{~min}$ before the testing session] on memory acquisition and retrieval by monkeys in the "object-inplace" visual memory task, an analog of human episodic memory. Only a small increase in error rate was produced $(<3 \%)$, and this increase was observed in both retention and acquisition tests. This deficit is substantially smaller than the previously reported deficit after fornix transection in the same task, and is not specific to memory acquisition. In Experiment 2, we investigated the neuroprotective effect of CGP-40116. NMDA
(68 nmol) was injected into the right hippocampus, then CGP$40116(6 \mathrm{mg} / \mathrm{kg})$ was given intramuscularly, and then NMDA was injected into the left hippocampus. The area of cell loss in CA1 and CA3 fields was smaller in both hemispheres compared with unprotected monkeys (without CGP-40116). Thus, CGP40116 provides both retrograde and anterograde protection against NMDA neurotoxicity. These data (1) demonstrate that acquisition of episodic memories remains almost intact when an NMDA receptor antagonist is given in a dose sufficient to block NMDA receptors in the hippocampus, and (2) indirectly oppose the hypothesis that NMDA receptor-dependent LTP plays the key role in memory.

Key words: CGP-37849; episodic memory; excitatory amino acids; glutamate receptor pharmacology; NMDA receptor pharmacology; competitive NMDA receptor antagonists; excitotoxicity; neuroprotection; ischemic brain damage; LTP; primates
NMDA receptors are crucially involved in the induction of long-term potentiation (LTP) in many brain areas (Collingridge and Bliss, 1995). LTP has been proposed as a neural mechanism of memory, and NMDA receptor antagonists might therefore be expected to interfere with memory acquisition via blocking induction of LTP. On the other hand, activation of NMDA receptors is involved in the chain of pathophysiological reactions that leads to an irreversible neuronal damage during brain ischemia (Peruche and Krieglstein, 1993 ) and, therefore, NMDA receptor antagonists have a potential clinical use as neuroprotectors. As a pharmacological tool for the present investigation, we chose the NMDA receptor antagonist CGP-40116. This substance is chemically related to D-2-amino-5phosphono-pentanoic acid (D-AP5) but, unlike D-AP5, it crosses the blood-brain barrier and blocks NMDA receptors in the brain after systemic administration (Fagg et al., 1990). We examined the effect of CGP-40116 on memory acquisition (Experiment 1) and on NMDA neurotoxicity (Experiment 2).

\section{EXPERIMENT 1: EFFECT OF CGP-40116 ON ACQUISITION AND RETRIEVAL OF VISUAL-REWARD ASSOCIATIONS IN THE OBJECT-IN-PLACE MEMORY TASK}

LTP is an artificially induced long-lasting enhancement of synaptic transmission first reported in the hippocampus of the rabbit

Received Nov. 28, 1995; revised March 5, 1996; accepted March 21, 1996.

This work was supported by the Medical Research Council (UK). We thank Dr. Cesare Mondadori for advice and encouragement and for supplying us with CGP-40116.

Correspondence should be addressed to Sergei A. Gutnikov, Department of Experimental Psychology, Oxford University, South Parks Road, Oxford OX1 3UD, UK.

Copyright (C) 1996 Society for Neuroscience 0270-6474/96/164041-05\$05.00/0
(Lomo, 1966; Bliss and Lomo, 1973). Associative LTP, which occurs when concurrent stimulation of two inputs to the same neuron results in enhancement of the weak input, is a proposed neural mechanism of associative memory (Brown et al., 1990). The acquisition of some forms of LTP depends on activation of the NMDA subtype of glutamate receptors. NMDA receptor antagonists block the induction of LTP (Collingridge et al., 1983; Harris et al., 1984; Errington et al., 1987) but not the maintenance of previously acquired LTP (Brown et al., 1989). Administration of NMDA receptor antagonists can produce severe deficits in performance of certain learning tasks (Morris et al., 1986; Tonkiss et al., 1988; Willner et al., 1992). Furthermore, a resemblance between the effects of AP5 and the performance deficit observed in animals with surgical lesions of the hippocampus or fornix was emphasized in rodent studies (Morris et al., 1990; Lyford et al., 1993). This body of evidence taken together suggests the hypothesis that a memory system in the hippocampus uses NMDAdependent LTP as its mechanism for the acquisition of new memories.

If (1) induction of NMDA receptor-dependent LTP is an essential part of the learning process and (2) NMDA receptor antagonists block induction but not retention of LTP, then NMDA receptor antagonists should selectively block acquisition of new memories but not retention of memories that had been acquired before administration of the drug. Although neither blockade of LTP with NMDA receptor antagonists nor demonstration of LTP itself has ever been performed in primates, it is plausible to assume a similarity of mechanisms of memory between rodents and primates. In other words, in accordance with the LTP-memory hypothesis it is plausible to assume that block- 
ade of the NMDA receptors should impair acquisition of hippocampus-dependent memories in primates. In the present experiment, we tested this prediction in monkeys by using the object-in-place memory task (Gaffan, 1994). In this task, it is possible to measure separately the retention of previously learned material and the acquisition of new memories within a single testing session. Furthermore, this task has been demonstrated to be highly sensitive to fornix transection (Gaffan, 1994). According to the hypothesis that NMDA receptor-dependent LTP is necessary for memory acquisition in the hippocampal formation, the predicted effect of the NMDA receptor antagonist in this task would be an impairment in the acquisition of new memories, but no impairment in retrieval of the previously learned material.

\section{MATERIALS AND METHODS}

\section{Subjects}

The subjcets wcre six malc rhcsus monkcys (Macaca mulatta). Their weights were $4.6,4.7,6.9,7.7,7.8$, and $9.0 \mathrm{~kg}$ at the beginning of the drug testing phase. All of the monkeys had previous extensive experience with the behavioral task.

\section{Apparatus}

The monkey was brought to the testing room in a wheeled transport cage, which was then fixed to the front of the apparatus facing a touch-sensitive computer monitor screen on which visual scenes (described below) were presented. The screen was $380 \mathrm{~mm}$ wide and $280 \mathrm{~mm}$ high and provided color VGA resolution $(640 \times 480$ pixels $)$. The monkey could reach out through the bars at the front of the transport cage to touch the screen, which was $\sim 150 \mathrm{~mm}$ from the front of the transport cage. Small food rewards (pellets, $190 \mathrm{mg}$ ) were delivered into a hopper placed centrally underneath the monitor screen. A single large food reward was delivered at the end of each training session by opening a box that was set to the left side of the centrally placed hopper. The box contained proprietary monkey food, peanuts, raisins, fruit, and seeds. The amount of this large reward was adjusted for individual animals to avoid obesity. The small and large rewards dispensed in the testing apparatus provided the entire daily diet of the monkeys. Opening of the box with the large food reward, like all other aspects of the stimulus display and the experimental contingencies during any session of training, was under computer control. A closed-circuit television system allowed the experimenter in another room to watch the monkey.

\section{Stimulus material}

Each scene occupied an entire screen. The background of cach scene was generated by drawing a random number (between 2 and 7) of randomly located ellipses and ellipse segments of random color, size, and orientation on a randomly colored initial background and then drawing a single large ( $\sim 180 \mathrm{~mm}$ high) randomly selected typographic character in a random color somewhere in the scene. The objects in the scene were two smaller ( $\sim 50 \mathrm{~mm}$ high) randomly selected typographic characters that were different from each other; they were drawn in random colors and at random locations with the constraint of a minimal spatial separation between therr. All of the random colors were assigned with the constraint that the objects should be visible at any location in the scene (that is, there was a minimum separation in color space between the colors of the foreground objects and the color of any element of the background). Examples of these visual scenes were reproduced in color in Gaffan (1994).

\section{Reinforcement contingencies}

Onc of the objects in each scene was designated as "correct" (a response to it was rewarded with a $190 \mathrm{mg}$ food pellet) and the other as "wrong" (a response to this object was followed by a $20 \mathrm{sec}$ timeout); there was also visual feedback: flashing of the correct object for $3 \mathrm{sec}$ after a correct response and immediate blanking of the screen after a wrong response. The location and the designations of the objects remained constant every time the scene was presented. The intertrial interval was $10 \mathrm{sec}$. Touching the screen during intertrial interval reset the interval. Touching any part of a displayed scene that was not one of the foreground objects in that scene resulted in scene blanking, an intertrial interval, and the presentation again of the same scene for the same trial. These "inaccurate" touches were recorded separately from errors (that is, choices of the negative object) and were made on $<1 \%$ of trials by all animals.

There was one testing session every day, $7 \mathrm{~d} /$ week. In each session, 20 new scenes were presented. Fach session consisted of two parts: (1) retention test ( 1 trial per scene) of the 20 scenes learned on the previous day, and (2) learning of new scenes ( 8 trials per scene organized as 8 repetitions of the entire sequence of 20 scenes). The level of retention of previously learned material was measured by counting the number of errors in the retention test; the rate of new learning was measured by counting the total number of errors across repetitions $2-8$ (because the responses at the first presentation of the scenes are random) and by the retention test of these scenes on the day after the injection day.

Correction trials were given only if the response in the first acquisition trial was wrong: after a $15 \mathrm{sec}$ delay during which the screen remained blank, the same background with only the correct object was presented. No correction trials were given in the subsequent acquisition except the very last trial in the session because the large reward at the end of the session (see Apparatus) could be given only after a correct response. The animals were trained until their performance stabilized, and then the drug testing commenced.

\section{Drugs}

CGP-40116 (D-isomer of CGP-37849: (E)-2-amino-4-methyl-5-phosphono3-pentenoic acid) was obtained from Ciba-Geigy (Basel, Switzerland). The drug powder was dissolved in physiological saline immediately before injection. The solution was injected into a femoral muscle in the volume of 0.1 $\mathrm{ml} / \mathrm{kg} 15 \mathrm{~min}$ (doses $0.03-3.0 \mathrm{mg} / \mathrm{kg}$ ) and $60 \mathrm{~min}$ (doses $3.0-6.0 \mathrm{mg} / \mathrm{kg}$ ) before testing session commenced. The dose of the drug was increased in steps: $0.03,0.1,0.3,1.0,3.0$, and $6.0 \mathrm{mg} / \mathrm{kg}$. If an animal stopped responding after a particular dose, the dose for the next drug injection was reduced. The main data were obtained from the block of tests with $6.0 \mathrm{mg} / \mathrm{kg}$.

Days when injections were given were alternated with no-injection days. On the injection days, CGP-40116 (drug condition) or saline (control condition) was administered; the order of drug and control conditions was pseudorandom (within-subject experimental design).

\section{RESULTS}

One of six monkeys stopped working in the behavioral task after administration of CGP-40116 in the dose of $6 \mathrm{mg} / \mathrm{kg}$, and another monkey did not complete the session even with the dose as low as $3 \mathrm{mg} / \mathrm{kg}$; those two animals were excluded from the further testing. The remaining four monkeys were tested with $6 \mathrm{mg} / \mathrm{kg}$ twice ( 2 subjects) or 5 tinnes ( 2 subjects). The data from individual subjects were collapsed across sessions for further analysis.

In the control condition (saline), on the injection day the retention of scenes that had been learned on the previous day was good: only $12 \%$ of errors on average (the open bar in Fig. 1, left). The learning curve for the new set of 20 scenes began at the chance level of $50 \%$ errors (not shown on the graph) and declined to practically perfect accuracy on the 8th repetition of the set (open symbols in Fig. 1, left). On the no-injection days that followed the saline injections, the pattern of results was exactly same (open symbols in Fig. 1, middle).

When CGP-40116 was injected, on the injection day the number of errors was higher, both in the retention test and in the new acquisition trials (closed bars and symbols in Fig. 1, left). However, the increase in errors was only $2.7 \%$. On the next day, i.e., when the information that had been learned on the drug day had to be retrieved, the number of errors in the retention test $(R)$ was higher than under the control condition by $7 \%$ (closed bar in Fig. 1 , middle). ANOVA revealed significant difference between the drug and control conditions $\left(F_{(1,3)}=53.27, p<0.01\right)$, between the injection day retention, new learning, and the next day retention phases $\left(F_{(2,6)}=13.69, p<0.01\right)$, but only nonsignificant drug $\times$ phase interaction $\left(F_{(2,6)}=5.05 ; 0.05<p<0.1\right)$. Acquisition of new scenes on the day after injections (Fig. 1, middle, trials 2-8) was the same after injection of CGP-40116 and after saline injec- 


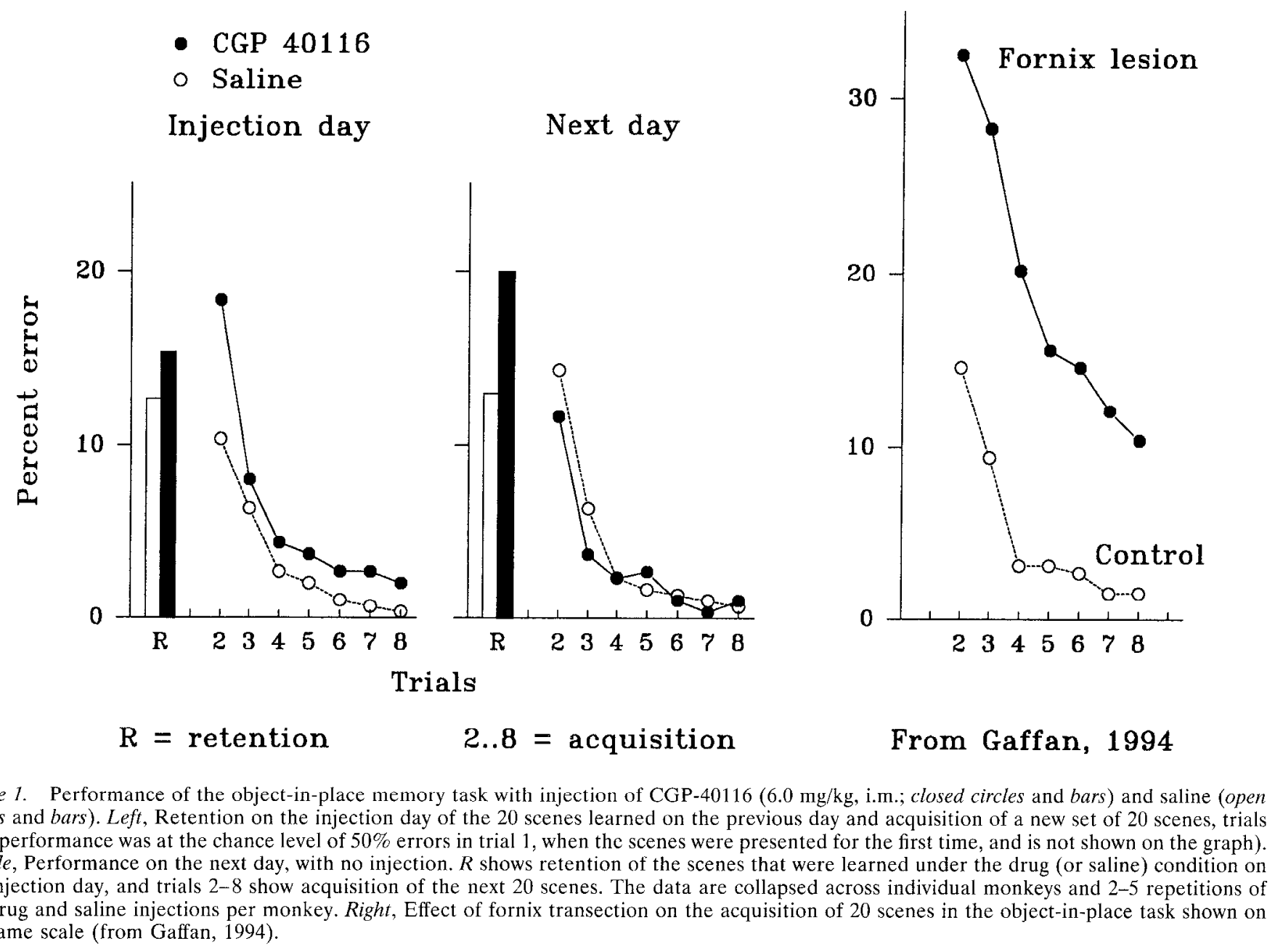

tion. This result confirms that $24 \mathrm{hr}$ is enough time for the direct effect of drug injection to dissipate.

\section{DISCUSSION}

When the performance deficit induced by injections of CGP. 40116 in the present experiment is compared with the earlier reported deficit in the same task after fornix transection (Gaffan, 1994), it becomes clear that the effect of the NMDA receptor antagonist is just a small fraction of the effect of a surgical fornix transection (compare with the right panel in Fig. 1). Even that small drug-induced impairment did not show clear specificity for acquisition of new memories, but produced also an effect on retrieval of old memories. The results of Experiment 1 suggest that blockade of NMDA receptors does not induce selective impairment of memory acquisition.

However, another possibility is that CGP-40116 as administered in the present experiment (injection of $6 \mathrm{mg} / \mathrm{kg}$, i.m.) does not block NMDA receptors in the monkey's hippocampus. We had no access to any published or unpublished data on the effect of CGP-40116 in rhesus monkey. In the only available study of this drug in primates, CGP-37849 (a racemic mixture of CGP-40116 with its inactive enantiomer) was administered to baboons in a range of doses up to $40 \mathrm{mg} / \mathrm{kg}$ (p.o.). That dose (equivalent of $20 \mathrm{mg} / \mathrm{kg}$ CGP-40116) protected baboons against photically induced mioclonus, whereas lower doses (equivalent to 10 and 5 $\mathrm{mg} / \mathrm{kg}$ ) were ineffective (Chapman et al., 1991). The different route of administration in that study makes difficult to compare the effective dose with the dose we empirically chose for our work. However, Shors and Servatius (1995) reported that a dose of as low as $5 \mathrm{mg} / \mathrm{kg}$ (i.p.) CGP-37849 (equivalent to $2.5 \mathrm{mg} / \mathrm{kg}$ CGP40116) was effective to block stress-induced facilitation of the conditioned eye-blink response in rats, whereas Massieu et al. (1993) demonstrated in the rat that systemic parenteral administration of CGP-40116 (ED $507.5 \mathrm{mg} / \mathrm{kg}$, i.p.) protected neurons against local administration of quinolinic acid, a neurotoxin acting primarily via NMDA rcceptors, even when CGP-40116 had been administered up to $6 \mathrm{hr}$ after quinolinic acid. In the next experiment, we tested whether CGP-40116 in the dose we used in our behavioral experiment could cause neuroprotection against NMDA neurotoxicity in the rhesus monkey.

\section{EXPERIMENT 2: NEUROPROTECTIVE EFFECT OF CGP-40116}

The aim of the present experiment was threefold: (1) to replicate the NMDA-induced neurotoxic lesion of hippocampal pyramidal cells in the rhesus monkey under barbiturate anesthesia; (2) to find out whether systemic administration of CGP-40116 protects against NMDA neurotoxicity; and (3) if such protection by CGP40116 is observed, to rule out the argument that the lack of specific effect on memory acquisition observed in the Experiment 1 was simply attributable to the lack of any central action of the drug after its systemic administration. 


\section{MATERIALS AND METHODS}

Subjects

Five rhesus monkeys (Macaca mulatta) were used in this experiment. They included four males with weights $3.5,6.9,8.7$, and $14.8 \mathrm{~kg}$, and one female with weight $12.5 \mathrm{~kg}$. None of these monkeys had taken part in Experiment 1. All five received injections of NMDA bilaterally in the hippocampus. Three of the animals (the "protected" animals) received in addition an injection of CGP-40116, whereas the other two (the "unprotected" animals) received no such injection, as described below.

\section{Surgery}

After ketamine premedication $(20 \mathrm{mg} / \mathrm{kg}$, i.m., ketamine hydrochloride; Vetalar, Park Davies Veterinary, Pontypool, Gwent, UK), barbiturate anesthesia was maintained by intravenous injections of $5 \%$ solution of thiopentone sodium (Intraval Sodium, Rhône Mérieux Ltd, Harlow, Essex, UK), $0.5 \mathrm{ml}$ ( $25 \mathrm{mg}$ ) every 15-20 min. Additional medication included, in the beginning of the operation: atropine (Martindale Pharmaceuticals, Romford, Essex, UK) $0.516 \mathrm{mg}$ (i.m.), bicillin (Brocades Great Britain Ltd., West Byfleet, Surrey, UK) 300,000 U (i.m.), dexamethasone sodium phosphate (Decadron, Merck, Hoddesdon, Hertfordshire, UK) $3.3 \mathrm{mg}$ (i.m.); at the end of the operation: buprenorphine hydrochloride (Temgesic, Reckitt and Colman Products Ltd, Hull, UK) $0.1 \mathrm{mg}$ (i.m.).

After coronal skin incision, a $4 \times 2.5 \mathrm{~cm}$ D-shaped bone flap was removed over the right temporal lobe. Cortex in the upper bank of the superior temporal sulcus was removed by aspiration, and the lateral ventricle was opened to expose the superior surface of the hippocampus. The stereotaxic coordinates of the hippocampus were recorded under visual guidance. Three injections of NMDA (Sigma-Aldrich Company Ltd, Poole, Dorset, UK), in a concentration of $10 \mathrm{mg} / \mathrm{ml}$ phosphate buffer, $\mathrm{pH} 7.3$, were made at $\sim 10.7 \mathrm{~mm}$ anterior to the ear-bar zero, 2 $\mathrm{mm}$ deep into the hippocampus, and $17,15.5$, and $14 \mathrm{~mm}$ lateral from the midline. The total volume injected at each site was $1.0 \mu \mathrm{l}$ (total dose of NMDA $68 \mathrm{nmol}$ ); $0.2 \mu \mathrm{l}$ was injected cvery $30 \mathrm{scc}$, and when the total of $1.0 \mu \mathrm{l}$ had been injected the needle was left in place for $2 \mathrm{~min}$. The three injections took $30 \mathrm{~min}$ altogether; the period of time between ketamine injection and first NMDA injection was between 220 and $310 \mathrm{~min}$. Then the right bone flap was temporarily replaced and an identical bone flap was taken over the left hemisphere. In the three "protected" animals, a single dose of $6 \mathrm{mg} / \mathrm{kg} \mathrm{CGP}-40116$ was injected into a femoral muscle 20 , 40 , and $112 \mathrm{~min}$ after the last NMDA injection on the right side. The "unprotected" animals received no injection of CGP-40116. The surface of the left hippocampus was then exposed, and a set of three NMDA injections was repeated on the left side; that set commenced 75,130 , and $49 \mathrm{~min}$ after the CGP-40116 injection in the three protected animals, respectively. When injections were completed, the dura was sutured, the bone flaps were replaced and sutured to the skull, the temporal muscles, galca, and skin were suturcd, and the animal was allowed to rccover.

Seven days later, the animal was deeply anesthetized and perfused with formol-saline, the brain was removed, fixed, sectioned at $50 \mu \mathrm{m}$ intervals, and stained with cresyl violet. The assessment of neurotoxic lesion was made by reconstruction of the area (in $\mathrm{mm}^{2}$ ) of clearly visible pyramidal cell loss. In each coronal section in which cell loss was visible, the length of the cell loss was measured in the pyramidal cell layer, and the integration of these lengths across all the sections gave the estimate of area of loss in the pyramidal cell layer.

\section{RESULTS}

Injection of NMDA produced cell loss in the pyramidal cell layer. The area of cell loss was smaller in the animals injected with CGP40116 than in the control animals (see Fig. 2). The difference between the control hemispheres (animals without injection of CGP40116) and the protected hemispheres was statistically significant for both anterograde and retrograde protection (one-tailed Wilcoxon's rank-sum test, $W_{\mathrm{s}}=6, p=0.05$ ). It also appeared that the area of cell loss was smaller when the tip of the needle was in the region CA3 than in the region CA1. Hemispheres in which the needle tip was in $\mathrm{CA} 3$ are marked in Figure 2 with an asterisk.

\section{DISCUSSION}

Systemic administration of CGP-40116 in the same dose as in Experiment 1 conferred substantial protection against the neuro-

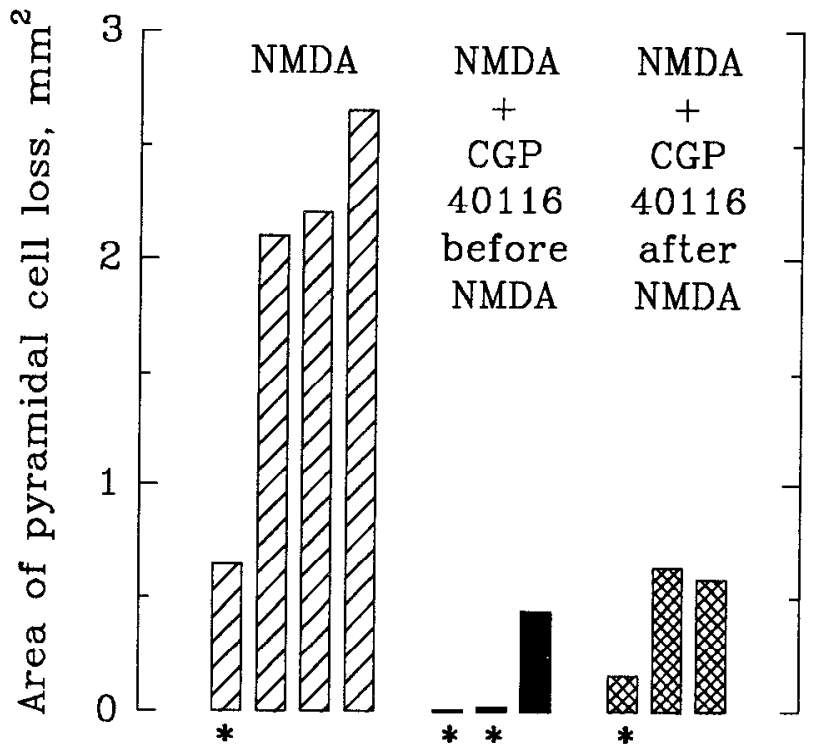

Figure 2. The area of cell loss in the CA1 and CA3 areas of the hippocampus after administration of $68 \mathrm{nmol}$ of NMDA alone (left four bars: 2 subjects, 4 hemispheres), NMDA after pretreatment with $6 \mathrm{mg} / \mathrm{kg}$ (i.m.) CGP-40116 (middle three bars: 3 subjects, 1 hemisphere from each subject), and NMDA followed by treatment with CGP-40116 (right three bars: the same 3 subjects, the other hemisphere from each subject). In the hemispheres marked with an asterisk, the needle tip was in the CA3 field, and in the other hemispheres it was near the CA1 field of the hippocampus.

toxic effects of NMDA. We observed both anterograde protection (in the hemispheres in which NMDA was injected after systemic administration of CGP-40116) and retrograde protection (in the hemispheres in which NMDA was injected before CGP-40116), as shown in Figure 2.

In both the protected and the unprotected animals, the area of cell loss was smaller, relative to other hemispheres in the same group of animals, when the tip of the needle was in the region CA3 (marked on Fig. 2 with an asterisk) rather than in the region CA1. There is a greater density of the NMDA receptors in the $\mathrm{CA} 1$ region than in the $\mathrm{CA} 3$ region in the primate brain (Perry et al., 1993), and this may account for the fact that NMDA in a given concentration killed more cells in CA1 than in CA3. Whatever the reason is for the difference in the size of neurotoxic lesion between CA1 and CA3 regions, the difference between protected and nonprotected hemispheres becomes even more salient when the location of the needle is taken into account.

\section{GENERAL DISCUSSION}

In Experiment 1, systemic administration of CGP-40116 in monkeys resulted in only a very small impairment of performance of the object-in-place memory task, which had been shown to be sensitive to fornix transection. This small impairment was not specific to the acquisition of new memories, because there was no significant difference between effects on acquisition and on retrieval. In Experiment 2, the same dose of CGP-40116 as that used in Experiment 1 led to clear anterograde and retrograde protection against NMDA neurotoxicity in the hippocampus.

In the task used in Experiment 1, the monkeys learned a new set of scenes within each session of training, and retention of those scenes was then tested in one trial per scene in the next day's session. This one-trial test is an uncontaminated measure of retention, because no effect of further learning is possible in a 
single trial. Thus, we could measure separately two specific effects of a single drug injection: its specific effect on retrieval of memories, as revealed in the retention test performed under the drug, and its specific effect on acquisition of new memories, as revealed by the retention test next day of the scenes that were learned under the drug. Furthermore, because the tests of acquisition and of retrieval were operationally identical (both were one-trial retention tests), they were of equal sensitivity. This allowed us to test the specific hypothesis, derived from the work on LTP discussed in the introductory remarks, that an NMDA receptor antagonist should impair acquisition but not retrieval of memories. The results failed to support this hypothesis. Although acquisition was impaired by the drug, as revealed by the increase in errors in the retention test on the day after drug injection, the effect on acquisition was mild and was not significantly greater than the effect on retrieval as measured by the increase in errors in the retention test on the drug day.

The effects of NMDA receptor antagonists on memory have been studied in several experiments with rodents. In some experiments, such drugs have produced behavioral effects resembling the effects of hippocanipal lesions (Morris et al., 1986; Lyford et al., 1993), but it is generally accepted that the interpretation of such effects depends on a distinction between drug effects on memory and drug effects on performance, and that this distinction is difficult to make in many of the existing experiments (Gallagher, 1990; Keith and Rudy, 1990; Morris, 1990; Deacon and Rawlins, 1995). The use in the present study of a pure measure of retrieval of memory, as opposed to acquisition of memory, allows effects on performance to be distinguished clearly from effects on memory acquisition.

Several experiments with rodents have cast doubt on the idea that NMDA receptor-dependent LTP is the basis of associative learning (Keith and Rudy, 1990; Bolhuis and Reid, 1992; Deacon and Rawlins, 1995; Gutnikov and Rawlins, 1996); and the evidence is growing that acquisition of new memories even in classical hippocampus-dependent tasks, such as spatial learning in a watermaze, is not impaired by NMDA receptor antagonists, providing that the animals had had extensive drug-free training (Bannerman et al., 1995; Saucier and Cain, 1995). The present study extends the latter evidence to the primate brain.

A second important outcome from of the present study, which may have implications not only for fundamental neuroscience but also for clinical research, is an empirical demonstration of substantial neuroprotective effect of a systemic NMDA receptor antagonist in the monkey.

\section{REFERENCES}

Bannerman DM, Good MA, Butcher SP, Ramsay M, Morris RGM (1995) Distinct components of spatial learning revealed by prior training and NMDA receptor blockade. Nature 378:182-186.

Bliss TVP, Lomo T (1973) Long-lasting potentiation of synaptic transmission in the dentate area of the anaesthetised rabbit following stimulation of the perforant path. J Physiol (Lond) 232:331-356.

Bolhuis JJ, Reid IC (1992) Effects of intraventricular infusion of the $N$-methyl-D-aspartate (NMDA) receptor antagonist AP5 on spatial memory of rats in a radial arm maze. Behav Brain Res 47:151-157.

Brown TH, Ganong AH, Kairiss EW, Keenan CL, Kelso SR (1989) Long-term potentiation in two synaptic systems of the hippocampal brain slice. In: Neural models of plasticity: experimental and theoretical approaches (Byrne JH, Berry WO, eds), pp 266-306. San Diego: Academic.

Brown TH, Kairiss EW, Keenan CL (1990) Hebbian synapses: biophysical mechanisms and algorithms. Ann Kev Neurosci 13:475-511.
Chapman AG, Graham JL, Patel S, Meldrum BS (1991) Anticonvulsant activity of two orally active competitive $N$-methyl-D-aspartate antagonists, CGP 37849 and CGP 39551, against sound-induced scizures in DBA/2 mice and photically induced myoclonus in Papio papio. Epilepsia $32: 578-587$.

Collingridge GL, Bliss TV (1995) Memories of NMDA receptors and LTP. Trends Neurosci 18:54-56.

Collingridge GL, Kehl SJ, McLennan H (1983) The antagonism of amino acid-induced excitations of rat hippocampal $\mathrm{CAl}$ neurones in vitro. J Physiol (Lond) 334:19-31.

Deacon RMI, Rawlins JNP (1995) Fffects of the competitive NMDA receptor antagonist CGP 37849 on performance of reference and working memory tasks by rats. Eur J Pharmacol 280:239-242.

Errington ML, Lynch MA, Bliss TVP (1987) Long-tcrm potentiation in the dentate gyrus-induction and increased glutamate release are blocked by D-aminophosphonovalerate. Neuroscience 20:279-284.

Fagg GE, Olpe HR, Pozza MF, Baud J, Steinmann M, Schmutz M, Portet $\mathrm{C}$, Baumann $\mathrm{P}$, Thedinga $\mathrm{K}$, Bittiger $\mathrm{H}$, Allgeier $\mathrm{H}$, Heckendorn $\mathrm{R}$, Angst C, Brundish D, Dingwall JG (1990) CGP 37849 and CGP 39551: novel and potent competitive $N$-methyl-D-aspartate receptor antagonists with oral activity. Br J Pharmacol 99:791-797.

Gaffan D (1994) Scene-specific memory for objects: a model of episodic memory impairment in monkeys with fornix transection. J Cognit Neurosci 6:305-320.

Gallagher M (1990) Robinson et al. (1989) deserves another look. Psychobiology 18:258-260.

Gutnikov SA, Rawlins JNP (1996) Systemic NMDA antagonist CGP 37849 produces nonspecific impairment in a working memory task: the effect does not resemble those of AP5 and of lesions of the hippocampus or fornix. Neuropsychologia 34:311-314.

Harris EW, Ganong AH, Cotman CW (1984) Long-term potentiation in the hippocampus involves activation of $N$-methyl-D-aspartate receptors. Brain Res 323:132-137.

Keith JR, Rudy JW (1990) Why NMDA-receptor-dependent long-term potentiation may not be a mechanism of learning and memory: reappraisal of the NMDA-receptor blockade strategy. Psychobiology $18: 251-257$

Lomo T (1966) Frequency potentiation of excitatory synaptic activity in the dentate area of the hippocampal formation. Acta Physiol Scand 68[Suppl 227]:128.

Lyford GL, Gutnikov SA, Clark AM, Rawlins JNP (1993) Determinants of non-spatial working memory deficits in rats given intraventricular infusions of the NMDA antagonist AP5. Neuropsychologia 31:1079-1098.

Massieu L, Thedinga KH, McVey M, Fagg GE (1993) A comparative analysis of the neuroprotective properties of competitive and uncompetitive $N$-methyl-D-aspartate receptor antagonists in vivo: implications for the process of excitotoxic degeneration and its therapy. Neuroscience 55:883-892.

Morris RGM, Anderson E, Lynch GS, Baudry M (1986) Selective impairment of learning and blockade of long-term potentiation by an $N$-methyl-D-aspartate receptor antagonist, AP5. Nature 319:774-776.

Morris RGM, Davis S, Butcher SP (1990) Hippocampal synaptic plasticity and NMDA receptors: a role in information storage? Philos Trans $\mathrm{R}$ Soc Lond [Biol] 329:187-204.

Perry EK, Court JA, Johnson M, Smith CJ, James V, Cheng AV, Kerwin JM, Morris CM, Piggott MA, Edwardson JA (1993) Autoradiographic comparison of cholinergic and other transmitter receptors in the normal human hippocampus. Hippocampus 3:307-315.

Peruche B, Krieglstein J (1993) Mechanisms of drug actions against neuronal damage caused by ischemia: an overview. Prog Neuropsychopharmacol Biol Psychiatry 17:21-70.

Saucier D, Cain DP (1995) Spatial learning without NMDA receptordependent long-term potentiation. Nature 378:186-189.

Shors TJ, Servatius RJ (1995) Stress-induced sensitization and facilitated learning require NMDA receptor activation. NeuroReport 6:677-680.

Tonkiss J, Morris RGM, Rawlins JNP (1988) Intra-ventricular infusion of the NMDA antagonist AP5 impairs performance on a non-spatial operant DRL task in the rat. Exp Brain Res 73:181-188.

Willner J, Gallagher M, Graham PW, Crooks GBJ (1992) N-methyl-Daspartate antagonist D-APV selectively disrupts taste-potentiated odor aversion learning. Behav Neurosci 106:315-323. 